\title{
Volunteering in dementia care - a Norwegian phenomenological study
}

\author{
This article was published in the following Dove Press journal: \\ Journal of Multidisciplinary Healthcare \\ 2I February 2012 \\ Number of times this article has been viewed
}

\author{
Ulrika Söderhamn' \\ Bjørg Landmark ${ }^{2,3}$ \\ Live Aasgaard ${ }^{2}$ \\ Hilde Eide ${ }^{3}$ \\ Olle Söderhamn' \\ 'Center for Caring Research - \\ Southern Norway, Faculty of Health \\ and Sport Sciences, University of \\ Agder, Grimstad, Norway; ${ }^{2}$ Institute \\ of Research and Development \\ for Nursing and Care Services, \\ Municipality of Drammen, Drammen, \\ Norway; ${ }^{3}$ Faculty of Health Sciences, \\ Buskerud University College, \\ Drammen, Norway
}

Introduction: The number of people suffering from dementia will increase dramatically in the future, and this will be a great challenge and concern for health care services. It is assumed that volunteers will strengthen community health care services more in the future than they do today.

Aim: The aim of this study was to elucidate lived experiences of working as a volunteer in an activity center with adapted activities for home-dwelling people with early stage dementia.

Methods: Qualitative interviews were implemented in a group of nine female volunteers from an activity center in southern Norway. The interviews were recorded, transcribed verbatim, and analyzed with a descriptive phenomenological method.

Results: Volunteering in an activity center for home-dwelling people with early stage dementia was reported to provide experiences of being useful and feeling satisfied with performing a good job. It was an advantage for the volunteers to have had experiences from life in general, but also as a health professional or as being the next of kin of a dementia sufferer. It was important for the volunteers to focus on the dementia sufferer and show caring behavior, and interaction with and the appreciation of the health care professionals were also important. The volunteers were motivated by being able to have influence and participate in the planning of the work, to be a part of the social setting, and to learn. However, for some volunteers it was difficult to adjust to an appropriate role.

Conclusion: In order to promote volunteering in a caring context, mutual trust and freedom should be emphasized. Being conscious of important volunteer characteristics like their experiences, knowledge, and caring behavior, as well as a focus on the staff showing appreciation and providing feedback, may be the difference between success and failure.

Keywords: activity, early stage dementia, phenomenology, voluntary work

\section{Introduction}

It is expected that the number of people suffering from dementia will increase dramatically in the future. This will be a challenge, and is a great concern for health care services. Day care and residential living for people with dementia will be expensive as the number of sufferers increases. ${ }^{1}$ Therefore, it is of importance that governments and policymakers have a plan and strategy for being able to meet this future demand.

Anticipated challenges will include a shortage of staff and a lack of centers offering a social meeting place for people with dementia who live at home - these centers will be important for providing them with activities and meeting their psychosocial needs and should also provide relief for spouses and next of kin. To meet these needs and demands, it will be important to develop centers that can coordinate voluntary
Correspondence: Olle Söderhamn Center for Caring Research - Southern Norway, Faculty of Health and Sport Sciences, University of Agder, PO Box 509, NO-4898 Grimstad, Norway

Tel +4737233797

Email olle.soderhamn@uia.no 
work to support the work of health care services. ${ }^{2}$ According to Fratiglioni et al, ${ }^{3}$ social networks are important in the prevention of dementia. Therefore, a center staffed by both professionals and volunteers that could offer home-dwelling people with dementia an opportunity for activities and psychosocial support would be expected to provide benefits both for the individual and the community.

"Volunteering" is defined as activities in which time is given freely to benefit another individual, group, or organization. Furthermore, volunteering is part of a cluster of helping behaviors that entail more commitment than spontaneous help or assistance, but differ from informal care provided, for example, within the family or among friends. ${ }^{4}$ Volunteer work is often considered to be beneficial to the volunteers and it has been shown that it enhances their wellbeing $^{4,5}$ and also that people with greater well-being invest more time in volunteer service. ${ }^{5}$

To a great extent, volunteering is related to memberships in various types of associations and is often associated with age and other background factors. Three types of volunteering were identified in a study ${ }^{6}$ with data from 17 developed countries and 31 developing and ex-communist societies: (1) environmental, peace, third world, welfare, and health; (2) political parties, local, women, and labor unions; and (3) religion, youth, sports, professional, and cultural. Societies that have a strong emphasis on self-expression and not primarily on survival rank highly on all three types of volunteering and economic development tends to produce increasing levels of volunteering. ${ }^{6}$

Data on volunteering in the care of dementia sufferers within the health care sector appear to originate mostly from studies carried out in the Western world. A study from South Carolina ${ }^{7}$ regarding social model programs for adults with Alzheimer's disease revealed results from programs provided by volunteers. The offered activities were intended to be meaningful, respectful, and appropriate for the clients. Examples of activities, which were evaluated to be in line with the clients' preferences, included games, exercise, music, and reminiscence work, and also pet therapy. The volunteers could perform many of these activities and also help with preparing lunch, transporting clients, and being "friends" with the clients. A literature review by Eggermont and Scherder ${ }^{8}$ showed, among other things, that an exercise program for people with dementia, performed several times a week, may have positive effects on affective behavior, sleep, and functional ability. Participating in an exercise program for people with Alzheimer's disease, led by college students, was shown to provide benefits, including physical fitness, slower cognitive decline, and mood improvement. In addition, using students to deliver such an exercise program was found to be successful with regards to transportation, one-on-one supervision, and motivational support. ${ }^{9}$

Many volunteers can feel fear when facing people with Alzheimer's disease and this highlights the need for educational programs for volunteers who work among people suffering from dementia. ${ }^{10}$ Kelsey and Laditka ${ }^{7}$ found that social programs for people with Alzheimer's disease, provided by both professionals and volunteers who were trained to encounter people with dementia, could offer best practices regarding the clients' activity preferences. Furthermore, it has been found that collaboration between professionals and volunteers can result in mutual support and team strengthening for those involved. ${ }^{11}$

Voluntary work within health care services is not very common in the Nordic countries ${ }^{12}$ and, therefore, research regarding volunteers in dementia care is also rare. To our knowledge, no studies have been performed in Norway that describe the experiences of volunteers working with physical and social activities among dementia sufferers. The current research into volunteering in dementia care is therefore expected to be of considerable importance, especially given that it is anticipated that volunteers will be important for the strengthening of community health care services in the future.

\section{Aim}

The aim of this study was to elucidate lived experiences of working as a volunteer in an activity center with adapted activities for home-dwelling people with early stage dementia.

The research question was: What is the phenomenon "volunteering" as narrated by volunteers working in an activity center for home-dwelling people with early stage dementia?

\section{Methods Design}

In order to study and describe the phenomenon of volunteering in dementia care, a descriptive phenomenological approach was chosen, with interviews of volunteers. Phenomenology as a philosophy seeks to understand a phenomenon that can be experienced from the perspective of a conscious person who is undergoing the experience. Thus, a "phenomenon" is considered to be that which is present to the consciousness. ${ }^{13}$ 


\section{Informants}

Volunteers working in a new activity center in southern Norway were invited to participate in the study. The activity center offered adapted physical and social activities for home-dwelling people with early stage dementia. To recruit volunteers, the activity center was promoted in the local newspaper. Those who volunteered at the activity center were not members of any association, and freely participated as people with an interest in the care of people with dementia. They worked with professionals with specific competence in caring for people with dementia. The volunteers participated in a range of tasks with the individuals with early stage dementia, including doing exercises, performing games and sports, seeing movies, talking, drinking coffee, and singing together. The volunteers also prepared meals, but this was not performed together with the dementia sufferers.

When the volunteers started to work at the activity center they were informed about dementia. They were followed up continuously by an appointed person in the activity center and were also regularly invited to information meetings, meetings for planning their activities in the following month, and lessons about dementia.

Only active volunteers at the activity center were eligible for participating in the study and twelve people (all of whom were women) met this criterion. They were verbally informed about the study by the leader of the activity center and were also given written information together with a written request to participate. Three of the eligible volunteers chose not to participate in the study, while the remaining nine agreed to participate and supplied a signed consent form to one of the authors (BL). The nine informants were women with different professional backgrounds. Their ages ranged between 53 and 77 years, and they had been volunteers in the activity center between 6 and 8 months. Eight of them had had earlier experiences of voluntary work in different areas such as church, school, sport, or welfare and health. Two had had experiences of a relative having dementia. Characteristics of the informants are shown in Table 1.

\section{The interviews}

The informants were contacted and interview appointments were made, with all interviews performed in the activity center by two of the authors (BL and LA) between April and June 2011. Informants were encouraged to narrate one situation they had experienced as successful and one situation they had experienced as not successful when working with the dementia sufferers in the activity center. Follow-up questions
Table I Characteristics of the informants

\begin{tabular}{llll}
\hline Informants & Age (years) & Prior role & Current role \\
\hline 1 & 53 & $\begin{array}{l}\text { Childcare worker } \\
\text { Home economics } \\
\text { teacher }\end{array}$ & $\begin{array}{l}\text { Waitress } \\
\text { Retired }\end{array}$ \\
3 & 77 & Specialist nurse & Retired \\
4 & 71 & Office clerk & Retired \\
5 & 72 & Physician & Retired \\
6 & 73 & Manager & Manager \\
7 & 60 & Specialist nurse & Retired \\
8 & 69 & Office clerk & Retired \\
9 & 67 & Childcare worker & Retired \\
\hline
\end{tabular}

were used for clarification and elaboration, such as: "Can you tell me more about that?," "What did you mean?," "How did you think about that?," and "What did it mean for you?" The interviews lasted up to 60 minutes. They were recorded and transcribed verbatim.

\section{Data analysis}

The interview text was analyzed by a descriptive phenomenological research method according to Giorgi's steps of analysis: ${ }^{13}$

1. Read for sense of the whole. The interview text was read with a phenomenological scientific reduction to obtain a general understanding of the entire description.

2. Determination of meaning units. The text was demarcated into meaning units - that is, the transcribed text was marked each time there was a significant shift in meaning.

3. Transformation of the informant's natural attitude expressions into the language of health science. Each meaning unit, expressed in the informant's own words, was transformed, that is, expressed in language revelatory of the health science aspect of the lived-through experience with respect to the phenomenon studied. By a phenomenological procedure of free imaginative variation, these transformed meaning units were then synthesized into a consistent statement (a situated structure) about volunteering. This step is illustrated in Table 2 .

4. Writing a general structure. This was done by condensing all situated structures from the interviews into a general structure that was meant to depict the lived experience of the studied phenomenon in the study group. Lived meanings are based on an individual experience, but get expressed eidetically (ie, in a general way).

The findings of the study are presented as one general structure of the studied phenomenon and six invariant themes. 
Table 2 Examples of the transformation of the informant's natural attitude expressions into the language of health science

\begin{tabular}{ll}
\hline Interview text demarcated into a meaning unit & Transformation of the meaning unit \\
\hline "Now I have some experience from the coordination center for voluntary & Volunteers with experience from voluntary \\
services, because I have been active there for I0-I2 years ... Yes, I have & work should help the dementia sufferers to \\
some experience of what it means ... We volunteers, yes and others, & keep their self-respect. All of them should \\
too, of course, should help them [the dementia sufferers] to keep their & be expected to be encountered seriously \\
self-respect, as I see it. I think all shall take them seriously when they are & \\
$\begin{array}{l}\text { asking something and you shall expect to get a proper answer on the } \\
\text { question you have" }\end{array}$ & \\
"I try to be conscious about not to put words in the mouth of them & She tries to be conscious about not putting \\
[the dementia sufferers], and we have had training in the activity center & words in the mouths of the dementia \\
about how we shall handle and behave, so we do not override them by & sufferers or pushing them to answer \\
putting words in the mouth on them or push them to answer" &
\end{tabular}

\section{Ethical considerations}

The researchers were guided by ethical standard principles ${ }^{14}$ and the intentions of the Declaration of Helsinki ${ }^{15}$ when they designed and performed the study. Confidentiality was assured and the informants had the opportunity to withdraw without declaring their reasons. Since no questions were asked in the interviews about the informants' own health status or about the health status of the people with dementia, there was no obligation in Norway to get approval from an ethical committee. The study was, however, reported to the Norwegian Social Science Data Services (Ref 26035) to confirm the correct handling and storage of collected data.

\section{Results}

\section{General description of volunteering}

Volunteering in an activity center for home-dwelling people with early stage dementia was reported to provide experiences of being useful and feeling satisfied with performing a good job. It was an advantage for the volunteers to have had experiences from life in general, but also as a health professional or as being the next of kin of a dementia sufferer. It was important for the volunteers to focus on the dementia sufferer and show caring behavior, and interaction with and the appreciation of the health care professionals were also important. The volunteers were motivated by being able to have influence and participate in the planning of the work, to be a part of the social setting, and to learn. However, for some volunteers it was difficult to adjust to an appropriate role.

\section{Being useful and feeling satisfied}

The volunteers had the feeling that they were of help to the people with dementia and had positive experiences when they interacted with them in the activity center or in connection with different outdoor activities such as games, sports, and walking. That they performed a good job was acknowledged by expressions of gratitude or a personal positive response from the target people, who also could show confidence in the volunteers. As a result, the volunteers perceived that their volunteering filled a need and they felt committed to the community work.

Furthermore, the volunteers felt that they did a good job and expressed feelings of satisfaction. It was a positive experience to be able to give something to other people, and the volunteers felt that they got back more than they gave. As a result of volunteering, life was experienced as more meaningful, and feeling useful and doing meaningful things resulted in a sensation of well-being. Moreover, when the people with dementia were satisfied, the volunteers were satisfied, too.

\section{Prior experiences}

When volunteers met people with dementia in the activity center it was considered valuable if those volunteers had had different life experiences, some experience with other voluntary work, or if they had a family member with dementia. This could make it easier to help those suffering from dementia keep their self-respect as it meant that volunteers would take them seriously. People who had been health professionals or who had experiences, interest, or knowledge of the care of older people - especially individuals with dementia - were more inclined to become volunteers in the activity center. The skills gained from such experiences were important to feeling safe in the role, especially when talking about dementia to the family of those suffering from the disease.

\section{Caring behavior}

A goal for the volunteers was to encounter the people with dementia as they themselves wanted to be met. The volunteers reported that they felt they should speak to the people, not put words in their mouths, and not push them to answer questions. The focus should be on the dementia sufferer, and 
the volunteers should not give themselves a place of honor. It was also important for the volunteer to be nice and friendly, a listener, and calm, but also to be able to give a hug. The volunteers wanted to create a pleasant atmosphere and ensure that the people with dementia in the center had a good day and that they felt safe and looked after. There was a scheduled program of meaningful activities that both volunteers and dementia sufferers participated in. The volunteers prepared meals without any assistance from the dementia sufferers. Besides the organized activities, the volunteers found it important to sit with the dementia sufferers, enjoying their company, and to talk with them as they would with anyone else (doing this around a table in connection to meals, for example). Talking face to face with an individual was also considered to be important. Group and one-on-one conversations were believed to produce good social manners and demonstrate that the dementia sufferer was being treated with respect. It was also mentioned that the volunteer had to be aware of the "chemistry" between the dementia sufferers and themselves, and ensure that their relationship was good. If the chemistry was not good, the volunteers felt that it would be better not to have a one-on-one conversation.

\section{Interaction with and appreciation from the staff}

A major positive experience of being a volunteer in the activity center was meeting with people with dementia. Additionally, being seen, heard, and affirmed by the staff at the center was also important. The volunteers felt welcome when they arrived at the center because the staff had a positive attitude toward them. Furthermore, the staff were generous in their praise of volunteers, which resulted in the volunteers feeling that they had had satisfying days at the center. The staff were acknowledged by the volunteers to be good leaders and professionals. Interactions between the staff and volunteers were good, with the staff providing information, as well as advice and support that further motivated the volunteers. The staff were also acknowledged as being good at celebrating memorable days and occasions, which made the days pleasant for the dementia sufferers.

\section{Motivating circumstances}

It was motivating for the volunteers to be invited to participate in meetings that were arranged for the volunteers once a month. In these meetings, they had the opportunity to influence their own working plan and reported that the staff were flexible and that their own needs were met. The social aspect of volunteering was another motivating factor - the volunteers reported that working together was a positive experience and it was useful to exchange experiences. It was also positive that they were invited to courses and seminars, and were given the opportunity to learn more about dementia and what it is like to live with such a disease.

\section{Difficulties in adjusting to the role}

One of the volunteers gradually realized that she did not have the personal resources to work with this particular target group, reporting that to be a volunteer she had to possess a resource "inside" herself, and since she felt sadness when she saw the people with dementia, their spouses, and their struggles, she could not find the inner strength that she felt she needed to do the work. She could not avoid thinking of the people with dementia when she was at home, so she decided to give up working as a volunteer in the activity center.

The volunteers also found it difficult to perform some tasks, such as doing everything necessary to cook dinner without any assistance. It was sometimes the case that only one volunteer was available to work in the kitchen, which meant that this one person found it hard to do a good job, and, as a result, they felt that there was a need for more volunteers.

Despite the fact that having experience as a health care professional was considered valuable when doing some tasks as a volunteer in the center, this experience was also found to have its disadvantages. Volunteers who were former health care professionals found that they did not have other professional colleagues or a paid role. This meant that these volunteers had professional knowledge that they were providing for free and were aware that some of the other volunteers did not all have the resources necessary to be a volunteer for people with dementia. Some volunteers with this background found it difficult to adjust to an appropriate role as a volunteer.

\section{Discussion}

The aim of this study was to elucidate lived experiences of working as a volunteer in an activity center with adapted activities for home-dwelling people with early stage dementia.

Overall, the informants reported that their experience of being volunteers in an activity center for people with early stage dementia was positive. They felt that there was a need for their voluntary contribution and, as a result, were committed in this type of community work. Life became more meaningful when they helped those who were less fortunate and, by giving something to the dementia sufferers, they got much more back. These seem to be motivating factors that are grounded in trust. 
They met individuals with dementia and treated them as they themselves would like to be treated, that is, according to the golden rule. ${ }^{16}$ This could be expressed according to Sartre ${ }^{17}$ in a phenomenological way - that is, the volunteers were seen and to some extent affirmed by the people with dementia, and their being-for-others depended on the values and situations of the dementia sufferers, that is, on their freedom. ${ }^{17}$ The individuals with dementia promoted an awareness among the volunteers that they were objects for others. Although the people with dementia may have had less freedom than the volunteers, because of their disease, the volunteers were dependent on the freedom of the dementia sufferers, and they were constituted as volunteers for the individuals with dementia. ${ }^{17,18}$ Being, seen as a fundamental, motivating, and critical issue, was also reflected in the interaction with and appreciation from the staff. The volunteers' being was dependent on the essential being of the others, that is, the people with dementia and also the staff. Being-for-others appeared to be a condition for beingfor-myself for the volunteers. ${ }^{17}$

Volunteering gave the volunteers' lives meaning and contributed to their identity, a finding that is consistent with the results of a study by Warburton and McLaughlin ${ }^{20}$ on older women as informal volunteers. Their informal caring provided them with many benefits, such as a personal strong role identity as aging caregivers, as well as helping the communities to be healthier and better to live in. This is also emphasized in other studies that show that volunteering enhances well-being, health, self-esteem, and life satisfac$\operatorname{tion}^{4,5}$ for the volunteers. It has been shown that volunteering is even associated with delayed mortality in older people. ${ }^{19}$

It was obvious in this study that professional caregivers had some difficulties in adapting to the role of volunteer. Professional knowledge, health care ethics, routines, and rituals in the health care sector and other issues may have been serious obstacles preventing former health care professionals taking on volunteer roles that in some ways were subordinate. In order to take advantage of these volunteers' knowledge and skills, staff should speak with volunteers and provide personal evaluations, and try to connect them more closely to the services in the activity center. A better understanding of volunteer characteristics and motivations will promote a more successful relationship between volunteers and staff ${ }^{11}$ and one of these important characteristics is having had a former professional role. If volunteering is to be a productive activity for aging people, attention needs to be paid to well-known barriers ${ }^{21}$ such as volunteer work that is considered boring or an ineffective use of the volunteers' skills and experiences. Since even people who are used to being around people with dementia may find it very difficult to work with people with the disease, it should be recommended that all volunteers receive proper training. In the present study, the volunteers were offered lessons about dementia, communication, coping, grief, and loss, as well as access to resources in the municipality related to the disease. However, it could be argued that the volunteer's attitude and personal qualities may be more important than knowledge and skills. ${ }^{22}$

As reported in the study by Warburton and McLaughlin, ${ }^{20}$ all informants in this study were women, and caring behaviors were a focus. The present study is limited in that no male volunteers were included, thus the volunteers' experiences may have been narrated differently if informants from both sexes had participated.

The rigor of this study is reflected in the systematic implementation of a descriptive phenomenological method. ${ }^{13}$ In the analyses, previous knowledge and theories about the phenomenon in focus were bracketed. Although this phenomenological reduction is almost impossible to fully implement, because we are human beings in the world with all its influences, ${ }^{23}$ we have tried to be conscious of it.

By using a phenomenological research method grounded in phenomenological philosophy, ${ }^{13}$ searching for key aspects of the phenomenon in focus, and applying the phenomenological reduction, the basis for validity in a phenomenological sense is present. The same meanings occurred consistently in the different interviews, so reliability of the findings was also obtained. ${ }^{24}$

The informants were considered to have sufficient experiences as volunteers in the activity center for people with early stage dementia to deliver varied and rich narratives of volunteering. This also means that the informants provided highly credible data. The general description of volunteering in this context should not be considered as complete, partly because possible male experiences of the phenomenon may be lacking. Nevertheless, it seems reasonable to transfer the findings to similar contexts.

"Volunteering" is a term that embraces many quite disparate activities ${ }^{4}$ and the phenomenon has been studied within various scientific traditions. It has been considered to be important for the development of cohesion and democracy in civilized societies. ${ }^{25}$ It is important to study volunteering within the health and caring sciences and, especially, to see it in a lifeworld perspective. There are already a number of subjectivist and behaviorist theories that attempt to explain volunteering, ${ }^{4}$ and many rigorous quantitative studies ${ }^{4,25}$ describe the phenomenon, its constituents, and influences. 
However, to let people narrate their lived experiences of the phenomenon in a special context in their own words may contribute with new knowledge. This knowledge can then be transferred to other similar settings and also further elaborated.

In conclusion, the lived experience of volunteering in an activity center for home-dwelling people with early stage dementia as narrated by the nine women in this study was a phenomenon with both positive and negative sides. Volunteering reflected relational aspects of being together, practical views, and freedom, and was a phenomenon experienced in relation to the whole context and not only to the group of individuals with early stage dementia. Mutual trust and freedom should be emphasized to promote volunteering in a caring context. A conscious approach to important volunteer characteristics, like their experiences, knowledge, and caring behavior, as well as a focus on the staff showing appreciation and providing feedback, may be the difference between success and failure. Further research is needed and this should focus on gender aspects as well as the dementia sufferers' and their next of kin's views of the phenomenon.

\section{Acknowledgment}

The informants and the staff at the activity center are gratefully acknowledged.

\section{Disclosure}

The authors report no conflicts of interest in this work.

\section{References}

1. Ferri CP, Pronce M, Broday H, et al. Global prevalence of dementia: a Delphi consensus study. Lancet. 2005;366:2112-2117.

2. Report no. 25 (2005-2006) to the Storting. Long Term Care - Future Challenges. Oslo: Ministry of Health and Care Services.

3. Fratiglioni L, Wang H-X, Ericsson K, Maytan M, Winblad B. Influence of social network on occurrence of dementia: a community-based longitudinal study. Lancet. 2000;355:1315-1319.

4. Wilson J. Volunteering. Аnпu Rev Sociol. 2000;26:215-240.

5. Thoits PA, Hewitt LN. Volunteer work and well-being. J Health Soc Behav. 2001;42(2):115-131.
6. Inglehart R. Modernization and volunteering. In: Dekker P, Halman L, editors. The Values of Volunteering. Cross-Cultural Perspectives. New York, NY: Kluwer Academic/Plenum Publishers; 2003:53-70.

7. Kelsey SG, Laditka SB. Evaluating best practices for social model programs for adults with Alzheimer's disease in South Carolina. Home Health Care Serv Q. 2005;24(4):21-46.

8. Eggermont LP, Scherder EJ. Physical activity and behaviour in dementia. Dementia. 2006;5(3):411-428.

9. Arkin SM. Student-led exercise sessions yield significant fitness gains for Alzheimer's patients. Am J Alzheimers Dis Other Demen. 2003;18(3):159-170.

10. Robinson KM, Clemons JW. Respite care - volunteers as providers. J Psychosoc Nurs Ment Health Serv. 1999;37(1):30-35.

11. Pritchard EJ, Dewing J. A multi-method evaluation of an independent dementia care service and its approach. Aging Ment Health. 2001;5(1):63-72.

12. Jeppsson Grassman E. På jakt efter den frivilliga sektorns roll inom nordisk äldreomsorg. Forskning, gestaltningar och perspektiv [In search of the voluntary sector's role in Nordic elderly care. Research, construction and perspective]. In: Szebehely M, editor. Äldreomsorgsforskningen $i$ Norden. En kunskapsöversikt [Elderly care research in the Nordic countries. A knowledge review]. TemaNord 2005:508. Copenhagen: Nordiska ministerrådet; 2005:281-320. Swedish.

13. Giorgi A. The Descriptive Phenomenological Method in Psychology. A Modified Husserlian Approach. Pittsburgh, PA: Duquesne University Press; 2009.

14. Beauchamp TL, Childress JF. Principles of Biomedical Ethics. 6th ed. New York, NY: Oxford University Press; 2008.

15. World Medical Association Declaration of Helsinki. Ethical Principles for Medical Research Involving Human Subjects. Seoul: World Medical Association; 2008. Available from: http://www.wma.net/ en/30publications/10policies/b3/index.html. Accessed January 5, 2012.

16. The Bible. Matthew 7:12.

17. Sartre J-P. Being and Nothingness. An Essay in Phenomenological Ontology. London: Routledge; 2001.

18. Morris KJ. Sartre. Oxford: Blackwell Publishing; 2008.

19. Harris AHS, Thoresen CE. Volunteering is associated with delayed mortality in older people: Analysis of the longitudinal study of aging. J Health Psychol. 2005;10(6):739-752.

20. Warburton J, McLaughlin D. Doing it from your heart: the role of older women as informal volunteers. J Women Aging. 2006;18(2):55-72.

21. Warburton J, Paynter J, Petriwskyj A. Volunteering as a productive aging activity: Incentives and barriers to volunteering by Australian seniors. J Appl Gerontol. 2007;26(4):333-354.

22. Ellis J. You've got a friend. Nurs Older People. 2010;22(5):9.

23. Merleau-Ponty M. The Phenomenology of Perception. London: Routledge and Kegan Paul; 1983.

24. Söderhamn O. Aspects of validity and reliability in a phenomenological sense. Theoria J Nurs Theory. 2001;10(2):12-16.

25. Dekker P, Halman L, editors. The Values of Volunteering. Cross-Cultural Perspectives. New York, NY: Kluwer Academic/Plenum Publishers; 2003.
Journal of Multidisciplinary Healthcare

\section{Publish your work in this journal}

The Journal of Multidisciplinary Healthcare is an international, peerreviewed open-access journal that aims to represent and publish research in healthcare areas delivered by practitioners of different disciplines. This includes studies and reviews conducted by multidisciplinary teams as well as research which evaluates the results or conduct of such teams or

\section{Dovepress}

healthcare processes in general. The journal covers a wide range of areas and welcomes submission from practitioners at all levels, from all over the world. The manuscript management system is completely online and includes a very quick and fair peer-review system. Visit http://www.dovepress.com/testimonials.php to read real quotes from published authors. 